\title{
FINITE ELEMENT MODELLING OF SEVERAL PHYSICAL ENGINEERING PROBLEMS
}

\author{
M. Abdel Wahab \\ Professor of Applied Mechanics \\ Ghent University, Laboratory Soete, Belgium
}

\begin{abstract}
This paper presents the application of the Finite Element Method (FEM) to a wide range of physical engineering problems and analysis types. It summarises some of the research works carried out by the author using FEM. The types of analysis, which are coved in this paper, include linear and non-linear stress analysis, heat transfer analysis, diffusion analysis, coupled thermal-stress and coupled diffusionstress analysis, fracture mechanics analysis and modelling of macro-cracks, fatigue damage initiation and crack propagation analysis, modal analysis, transient dynamics analysis and traffic flow analysis.
\end{abstract}

Keywords Finite Element Analysis, stress analysis, heat transfer, diffusion of moisture, coupled field analysis, fracture mechanics, fatigue, modal analysis, transient dynamics, traffic flow.

\section{INTRODUCTION}

The Finite Element Method (FEM), also known as Finite Element Analysis (FEA), is a numerical technique that can be used to solve partial differential equations and integral equations. The concept is simply based on replacing the partial differential equations by a system of simultaneous algebraic equations for steady state problems and a system of ordinary differential equations for time dependent problems. This can be done in two essential steps; a) writing the variational equivalent or weak form of the partial differential equation and $b$ ) replacing the infinite dimensional problem by a finite dimensional one through discretisation of the space. The resulting system of simultaneous equations can then be easily solved using a digital computer. One of the widely used techniques to convert the partial differential equations to algebraic equations is the variational formulation, also known as weighted residual formulation. For example, for a simple bar element, the governing differential equation for static analysis is given by:

$$
E A \frac{\partial^{2} u}{\partial x^{2}}-f=0
$$

Where $E A$ is the axial stiffness, $u$ is the displacement and $f$ is the applied distributed axial load. Both $u$ and $f$ are functions of the coordinate $x$. The variational equivalent or weak form of Equation (1) is given by:

$$
\int \phi(x)\left(E A \frac{\partial^{2} u}{\partial x^{2}}-f\right)=0
$$

Where $\phi(x)$ is a weigh function vector. Discretisation of the space is usually done by writing the displacement function in terms of the nodal displacements $[U]$ using interpolation functions or shape functions $[\mathrm{N}]$, which varies from 0 to 1 , so that:

$$
u=[N]^{T}[U]
$$

Substituting Equation (3) into Equation (2), using $\phi(x)=[N]$ as in the Galerkin Finite Element approach and solving by integration by parts, yields the well known FE equation:

$$
[K][U]=[F]
$$

Where $[K]$ is the stiffness matrix $\left([K]=E A \int_{0}^{1} \frac{\partial[N]}{\partial x} \frac{\partial[N]^{T}}{\partial x} d x\right),[U]$ is the displacement vector or degree-offreedom vector and $[F]$ is the force vector containing both the axial distributed load components and boundary conditions. FEM is originally developed in 1941 for stress analysis problems. Nowadays, it is applicable to many other physical engineering problems. Many textbooks on FEA and its applications are available in the literature, e.g. $[1,3]$. 


\section{STRESS ANALYSIS}

In stress analysis, the degrees of freedom are translations as in case of bar elements, plane elements and 3-D solid elements, and/or rotations as in case of beam elements, plate elements and shell elements. For linear elastic analysis, Equations (4) is solved for the degree-of-freedom vector for a given stiffness matrix and force vector. After obtained, the degrees of freedom, the strain components are calculated from the compatibility equation, i.e. the relationship between strains and the displacements or rotations, as follows:

$$
[\varepsilon]=[B \rrbracket U]
$$

Where $[B]$ is the strain-displacement or compatibility matrix. The stresses are then calculated from the strains using the constitutive equation or stress/strain relationship, i.e.

$$
[\sigma]=[D][\varepsilon]
$$

Where $[D]$ is the constitutive matrix. An example for linear elastic stress analysis for a hydraulic Manifold due to in-service system pressure is shown in Figure 1, where von Mises stress contour is plotted [4]. Due to symmetry, only half of the manifold was modelled using 3-D solid elements. The manifold was made of steel and the maximum applied pressure was $68 \mathrm{MPa}$.

In case of geometric non-linearity (large deformation) or material non-linearity (elastic-plastic), the stiffness matrix becomes function of the unknown degrees of freedom so that Equation (4) becomes:

$$
[K(U)][U]=[F]
$$

The solution cannot be obtained in one step and an iterative solution is required. Furthermore, due to the non-linear force-displacement or stress-strain behaviour, an incremental solution is necessary. Thus, the incremental solution for non-linear stress analysis problems becomes:

$$
\Delta \psi=[K(\Delta U)][\Delta U]-[\Delta F]
$$

Where $\Delta U$ is the incremental displacement vector, $\Delta F$ is the incremental force vector and $\Delta \psi$ is the incremental residual force vector, which should be equal to zero for a converged solution. The iterative solution is usually solved using Newton-Raphson method. An example for a large deformation analysis is shown in Figure 2, where the deformation of a road sweeping brush is plotted [5]. The brush was made of steel tines and modelled using beam elements. The deformed shape in Figure 2 is for a flat flicking brush, which is in contact with the ground and has a penetration of $50 \mathrm{~mm}$.

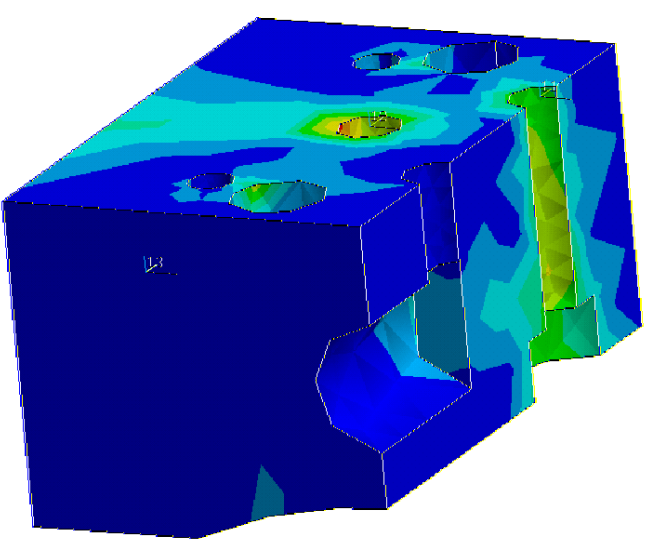

Figure 1. Linear elastic analysis of a Hydraulic Manifold - von Mises stress (MPa)

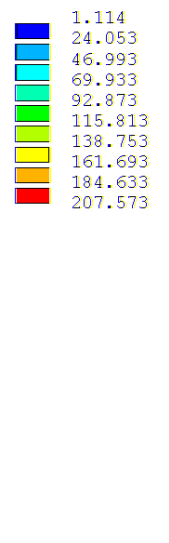

Figure 2. Large deformation analysis of a road sweeping brush - deformed shape

An example of material non-linearity finite element modelling is a thick walled tube subjected to autofrettage process [6], which is usually used in manufacturing barrels of handguns, rifles, artillery, and cannons mounted on military aircrafts. Autofrettage is carried out by means of an oversized mandrel or swage that is forced through the bore creating a region of plastic deformation. The mandrel is then withdrawn so that the elastic material surrounding the plastic zone attempts to return to its undeformed state. The material that is permanently deformed partially prevents this response. Hence a compressive residual hoop stress field is created at the inner surface of the tube. Figure 3 shows a plot of the residual hoop stress in a 2-D axsymmetric model of the thick walled tube. An elastic perfectly plastic material model was used and the autofrettage process was simulated through the application of an overstrain (overstrain is defined as $\delta=R_{m}-R_{i}$, where $R_{m}$ is the mandrel radius and $R_{i}$ is the inner radius of the tube). The overstrain has been applied to the tube by prescribing the corresponding interference at the inner wall side as initial 
boundary condition. The prescribed interference was applied gradually until it reaches its maximum value; then it was removed gradually in order to simulate the unloading process. The FE results are also compared to the analytical solution in Figure 3, for three different overstrain values, namely $\Phi=25,60$ and $100 \%\left(\phi=\frac{R_{m}-R_{i}}{R_{i}} \times 100 \%\right)$.
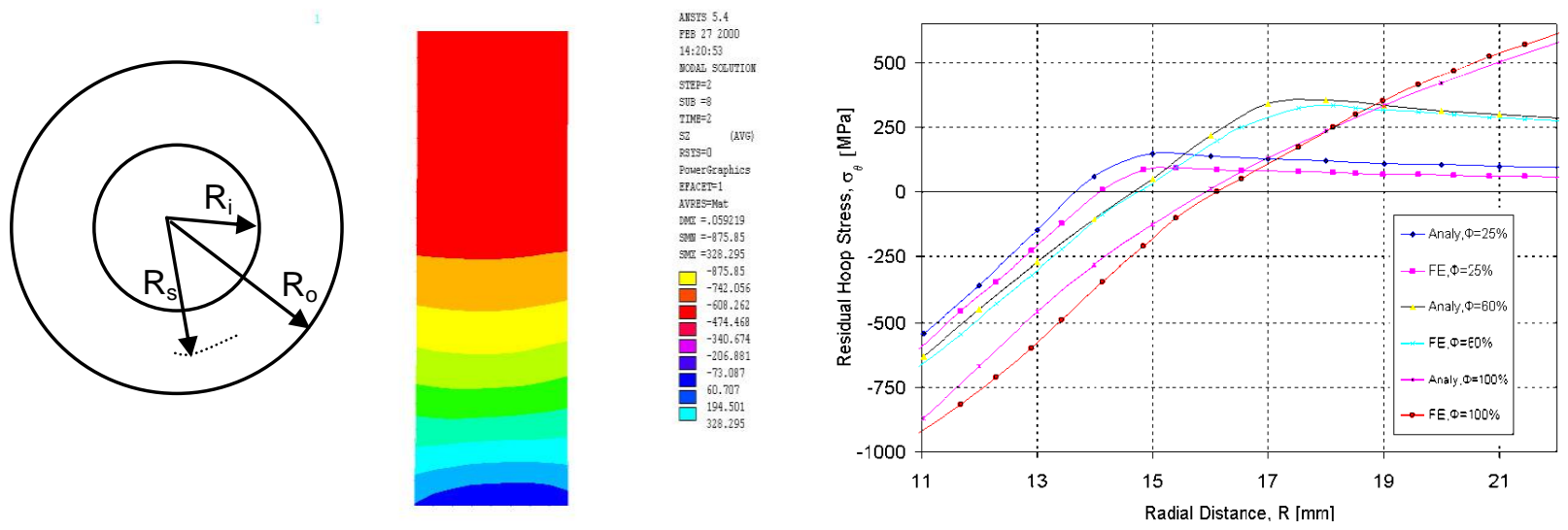

Figure 3. Residual hoop stress in an autofrettaged tube (MPa)

\section{HEAT TRANSFER ANALYSIS}

In heat transfer analysis, the degree of freedom is usually temperature. In general, there are two types of analysis, namely steady state analysis and transient analysis. In steady state analysis, the temperature distribution and related quantities are determined under steady state condition, i.e. variation over time is ignored. Whereas in transient analysis, the temperature distribution and related quantities are determined at different time intervals. The governing differential equation for isotropic heat transfer in 3-D space, also known as the heat equation, is given by:

$$
\frac{\partial T}{\partial t}=\frac{K}{c_{p} \rho}\left(\frac{\partial^{2} T}{\partial x^{2}}+\frac{\partial^{2} T}{\partial y^{2}}+\frac{\partial^{2} T}{\partial z^{2}}\right)
$$

Where $t$ is time, $K$ is thermal conductivity $\left(\mathrm{J} / \mathrm{m} .{ }^{\circ} .{ }^{\circ} \mathrm{C}\right.$ or $\left.\mathrm{W} / \mathrm{m} .{ }^{\circ} \mathrm{C}\right), \rho$ is mass density $\left(\mathrm{kg} / \mathrm{m}^{3}\right), c_{p}$ is specific heat capacity $\left(\mathrm{J} / \mathrm{kg} .{ }^{\circ} \mathrm{C}\right)$ and $T$ is temperature, which is function of space and time. Applying the variational formulation or weighted residual formulation to Equation (8), the FE conduction heat transfer equation is obtained as:

$$
[C]\left[\frac{\partial T}{\partial t}\right]+[K][T]=[q]
$$

Where $[K]$ is the conductivity matrix, $[C]$ is the specific heat matrix, $[T]$ is the temperature vector, $\left[\frac{\partial T}{\partial t}\right]$ is the rate of change of temperature vector over time and $[q]$ is the heat flux vector. Equation (9) is solved using numerical integration, usually Euler integration scheme, in which the derivative of temperature with respect to time is approximated as $\frac{\partial T}{\partial t}=\frac{T(t+\Delta t)-T(t)}{\Delta t}$, where $T(t+\Delta t)$ is the temperature at time step $t+\Delta t$ and $T(t)$ is the temperature at time step $t$. For steady state analysis, the problem is independent of time, thus the term concerned with time in Equation (9) is eliminated, and the FE equation is reduced to:

$$
[K][T]=[q]
$$

An example of steady state conductivity heat transfer FEA is a Railko Marine Bearing [7]. The bearing consists of two layers, namely a backing and a liner. The backing has a thermal conductivity of 0.35 $\mathrm{W} / \mathrm{m} .{ }^{\circ} \mathrm{C}$ and a thickness of $28 \mathrm{~mm}$, while the liner has a thermal conductivity of $0.22 \mathrm{~W} / \mathrm{m} .{ }^{\circ} \mathrm{C}$ and a thickness of $21 \mathrm{~mm}$. The average inner diameter is $740 \mathrm{~mm}$ and the outer diameter is $838 \mathrm{~mm}$. 2-D plane heat transfer elements were used to model the two layers with mesh refinement near sharp corners and at interface. The inside temperature was $100^{\circ} \mathrm{C}$, whereas the outside temperature was $30^{\circ} \mathrm{C}$. Figure 4 shows the steady state temperature distribution in the bearing. 

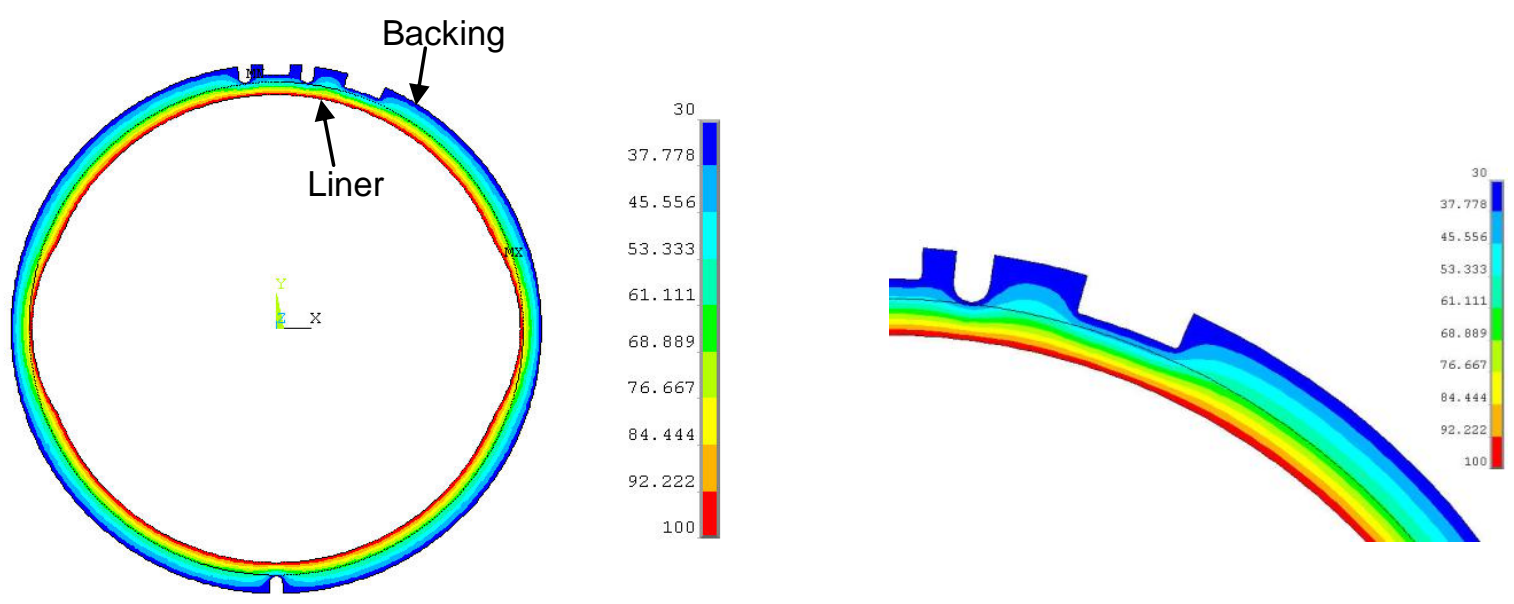

Figure 4. Steady state heat transfer analysis - Temperature $\left({ }^{\circ} \mathrm{C}\right)$ distribution in Railko bearing

\section{DIFFUSION ANALYSIS}

In diffusion FE analysis, the degree of freedom is moisture concentration. The general form of the governing differential equation for isotropic diffusion in 3-D space can be expressed as:

$$
\frac{\partial c}{\partial t}=D\left(\frac{\partial^{2} c}{\partial x^{2}}+\frac{\partial^{2} c}{\partial y^{2}}+\frac{\partial^{2} c}{\partial z^{2}}\right)
$$

Where $D$ is the diffusion coefficient $\left(\mathrm{m}^{2} / \mathrm{s}\right)$ and $c$ is the moisture concentration, which is a function of time and space. The moisture concentration $c$ (also denoted as $C / C_{\infty}$ ) is a dimensionless quantity and varies between 0 and 1 with a value of 0 indicating dry condition, and a value of 1 indicating fully saturated condition. We can easily notice the similarity between Equation (11) for diffusion analysis and Equation (8) for heat transfer. If we substitute by $c_{p} \rho=1, K=D$ and $T=c$ in Equation (8), it becomes identical to Equation (11). Therefore, the heat transfer FE equations for steady state analysis (Equation (10)) and for transient analysis (Equation (9)) are applicable to diffusion analysis. Furthermore, in commercial FE packages, a diffusion analysis can be performed using heat transfer element with different interpretation of the physical meaning of the degree of freedom and its related quantities. An example of a transient diffusion analysis is a lap strap joint [8] shown in Figure 5. The lap strap joint consists of two substrates made of carbon fibre reinforced polymer (CFRP) composite materials bonded together using adhesives. The adhesive layer has a rectangular fillet at the edge of the joint. The diffusion coefficient used in the analysis presented in Figure 5 for adhesive was $9.3 \times 10^{-13} \mathrm{~m}^{2} / \mathrm{s}$ and for the composite material was $3.6 \times 10^{-13} \mathrm{~m}^{2} / \mathrm{s}$. The transient diffusion analysis was performed in the commercial software ANSYS using heat transfer elements. As initial and boundary conditions, all edges including composites, adhesive and fillet are assumed to be saturated (i.e. all edges are exposed). The distribution of moisture concentration along the centre of the adhesive layer is plotted in Figure 5 after three different exposure times, 10, 20 and 30 days.
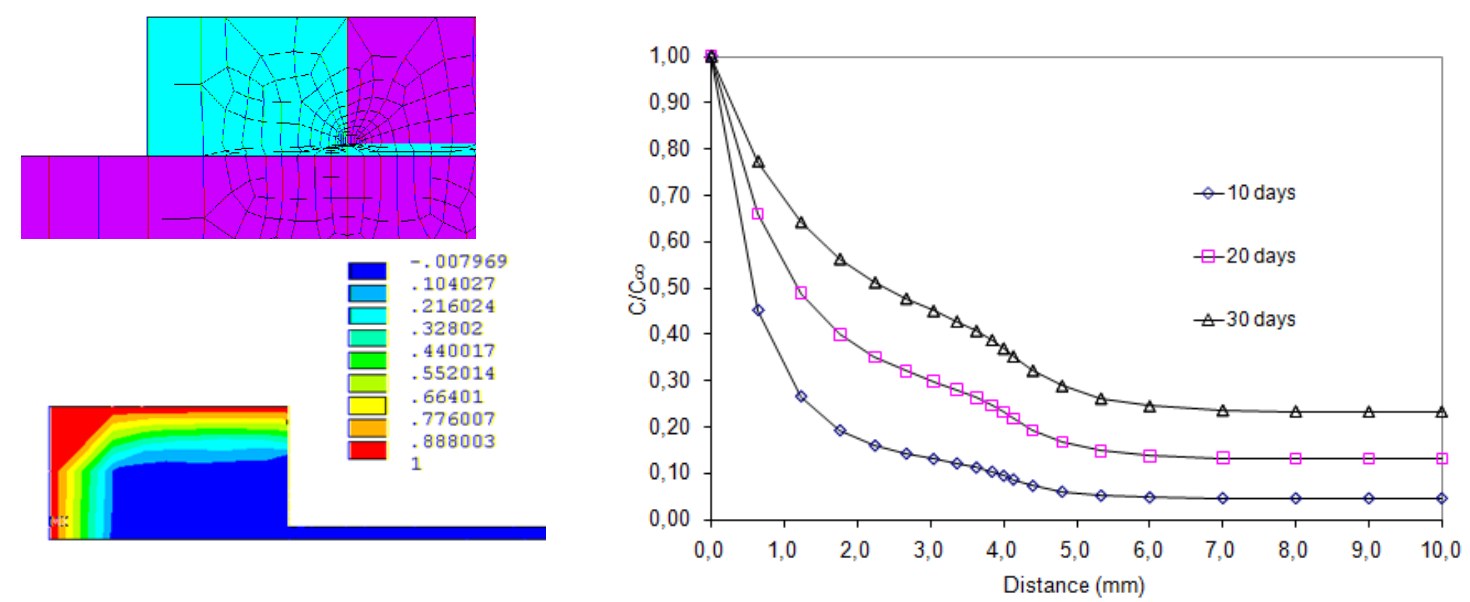

Figure 5. Transient diffusion FE analysis for a lap strap adhesive joint 


\section{COUPLED-FIELD ANALYSIS}

A coupled-field analysis, also known as multi-physics analysis, is a combination of two or more dependent analyses from different physics field. The output of one analysis would be the input for the next analysis. For example, after performing heat transfer analysis, the temperature distribution would generate thermal strains, which can be applied to a subsequent stress analysis. We present herein two examples of coupled field analysis, namely thermal-stress analysis and diffusion-stress analysis. The steps that are involved in performing the coupled field analyses are summarised in Figure 6(a). The same finite element mesh should be used for both heat transfer and stress analyses. However, the element type should be switched from heat transfer element to structural element. If the mechanical properties are thermal or moisture dependent, they have to be defined for each element according to its temperature or moisture concentration. The thermal strains ( $\varepsilon_{t}=\alpha \times \Delta T$, where $\alpha$ is the coefficient of thermal expansion and $\Delta T=T-T_{r e f}$ with $T$ the calculated temperature and $T_{\text {ref }}$ a reference or strain free temperature) or swelling strains $\left(\varepsilon_{d}=\alpha_{s} \times c\right.$, where $\alpha_{s}$ is the coefficient of swelling and $c$ is the moisture concentration) are calculated for each element. The mechanical loads, if any, are applied and the stress analysis is solved. The first example is the thermal-stress analysis of the Railko bearing [7] presented in section 3. The mechanical properties of the backing were Elastic modulus $E=37 \mathrm{GPa}$ and Poisson's ratio= $=0.3$ and for the liner: Elastic modulii $E_{x}=19$ $\mathrm{GPa}, E_{y}=39 \mathrm{GPa}, E_{z}=20 \mathrm{GPa}$ and Poisson's ratio=0.3, where $x$ is the radial direction, $y$ is the hoop direction and $z$ is the axial direction. A contour of the hoop stress due to only thermal strains is shown in Figure $6(b)$. The second example is the diffusion-stress analysis of the lap strap joint [9] presented in section 4. The mechanical properties for the adhesive were dependent on the moisture concentration. Therefore, the stress-strain response for each adhesive element was defined on the basis of the moisture concentration in the element. For CFRP composite substrates, the moisture didn't affect the mechanical properties. A mechanical load of $5 \mathrm{kN}$ was applied to the joint. A plot of the peel stress in the adhesive layer along the adhesive/substrate interface is shown in Figure 6(c). The joints were aged in hot/wet environment, $90^{\circ} \mathrm{C} / 97 \% \mathrm{RH}$ up to saturation (denoted as 90 wet in Figure $6(\mathrm{c})$ ) and tested in dry at $90^{\circ} \mathrm{C}$ (denoted as /dry) and wet $97 \% \mathrm{RH}$ at $90^{\circ} \mathrm{C}$ (denoted as /wet) conditions.

\begin{tabular}{|c|c|c|c|c|c|}
\hline $\begin{array}{c}\text { Heat transfer } \\
\text { or diffusion } \\
\text { analysis }\end{array}$ & $\begin{array}{c}\text { Switch element } \\
\text { type from heat } \\
\text { transfer to } \\
\text { structural element }\end{array}$
\end{tabular}$\quad \begin{gathered}\begin{array}{c}\text { Define thermal or } \\
\text { moisture dependent } \\
\text { mechanical } \\
\text { properties }\end{array} \\
\begin{array}{c}\text { Apply thermal } \\
\text { strains or swelling } \\
\text { strains and } \\
\text { mechanical loads }\end{array}\end{gathered} \|$\begin{tabular}{c}
$\begin{array}{c}\text { Solve } \\
\text { stress } \\
\text { analysis }\end{array}$ \\
\hline
\end{tabular}

(a)

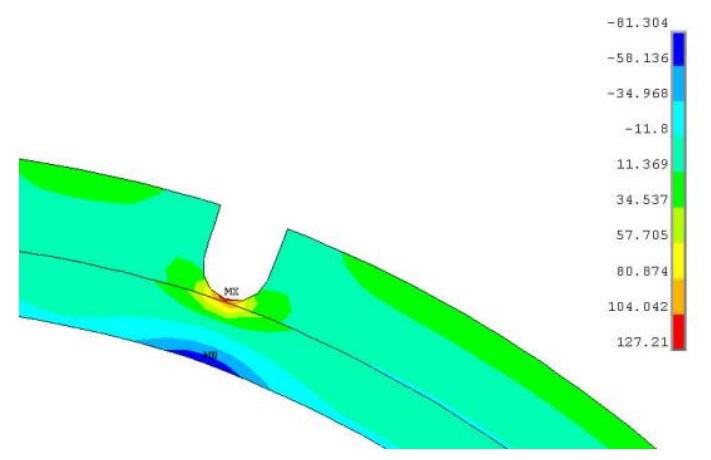

(b)

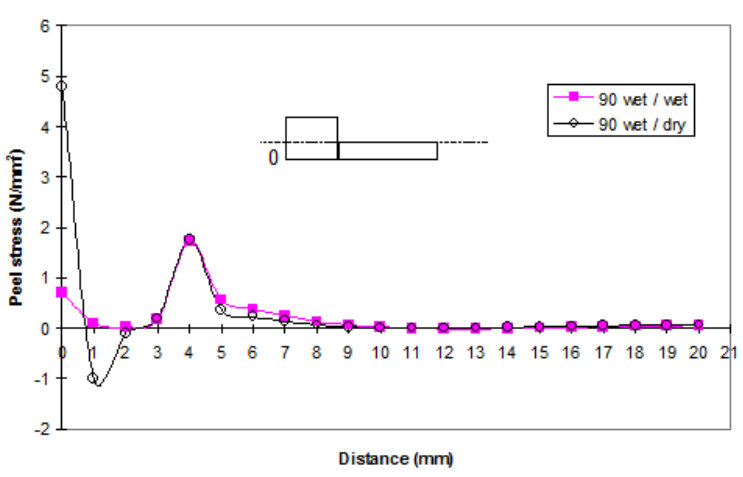

(c)

Figure 6. Coupled-field analysis: (a) Procedures, (b) Thermal-stress analysis of Railko bearing and (c) Diffusion- stress analysis of lap strap joint.

\section{FRACTURE MECHANICS ANALYSIS}

Fracture mechanics analysis using FEA involves two main steps, namely; a) modelling of macro-crack and b) extracting fracture mechanics parameters from stress analysis results. When modelling the crack in FEA, the crack faces should coincident but not connected together. The elements around the crack tip should be quadratic to capture the high stress and stain gradient near the crack tip, as shown in Figure 7(a). In Linear Elastic Fracture Mechanics (LEFM), the displacement variation near the crack tip is proportional to the square root of the distance from the crack tip $(u \propto \sqrt{r})$ and the stress and strain singularity is of the square 
root type ( $\sigma \propto \frac{1}{\sqrt{r}} \& \varepsilon \propto \frac{1}{\sqrt{r}}$ ). In such a case, the quarter point singularity elements [10], in which the midside nodes at the crack tip are shifted to the quarter position in order to produce square-root stress singularity, as show in Figure 7(b). In Elastic-Plastic Fracture Mechanics (EPFM), the stress singularity is not of the square root type and has an order of $1 / m+1$, where $m$ is the power law constant in the Ramberg-Osgood equation [11] $\left(\sigma \propto \frac{1}{r^{1 / m+1}}\right)$ and the strain singularity has an order of $\mathrm{m} / \mathrm{m}+1$ $\left(\varepsilon \propto \frac{1}{r^{m / m+1}}\right)$. Also, in composite materials when cracks terminate at an interface, the order of the singularity is no more of the square root type and has a general order $\lambda\left(u \propto r^{\lambda} \& \varepsilon \propto r^{\lambda-1}\right)$, which can be a real number $0 \leq \lambda \leq 1$, or a complex number, depending on the geometry of the problem and material properties. To approximate the general power type singularity in FEA, special crack tip elements as the one shown in Figure 7(c) have been developed [12, 13]. After obtaining the FE results, fracture mechanics parameters such as stress intensity factor, strain energy release rate and J-integral can be calculated. There are many computational techniques to extract fracture mechanics parameters from FE results. We present herein two simple techniques to calculate the stress intensity factor and the strain energy release rate using the nodal displacements behind the crack tip and the nodal forces ahead of it. Consider the arrangement of nodes in a quarter point element as shown in Figure 7(b), a two-point formula for calculating the stress intensity factor for a symmetric cark is given by [14]:

$$
K_{I}=\frac{E}{4} \sqrt{\frac{2 \pi}{L}}\left(4 u_{y_{i-1}}-u_{y_{i-2}}\right)
$$

Where $E$ is the Elastic modulus and $u_{y_{i-1}}$ and $u_{y_{i-2}}$ are the crack opening displacements of nodes $i-1$ and $i-2$, respectively. For the same arrangement of nodes shown in Figure $7(b)$, the strain energy release rates for mode I and mode II, derived from a virtual crack closure approach, are given by [15]:

$$
\begin{gathered}
G_{I}=\frac{2 u_{y_{i-1}}}{L}\left(F_{y_{i+1}}+(1.5 \pi-4) F_{y_{i}}\right) \\
G_{I I}=\frac{2 u_{x_{i-1}}}{L}\left(F_{x_{i+1}}+(1.5 \pi-4) F_{x_{i}}\right)
\end{gathered}
$$

Where $F_{x}$ and $F_{y}$ are the crack closure nodal forces in the $x$ and y directions, respectively, and $u_{x}$ and $u_{y}$ are the crack sliding and opening displacements, respectively. Deformation near an interface crack in a lap strap joint [16] is shown in Figure 7(d).

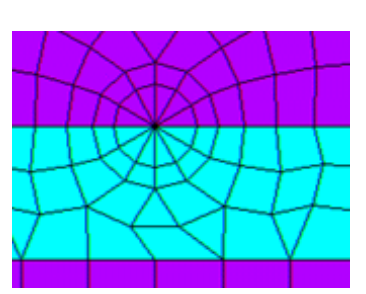

(a)

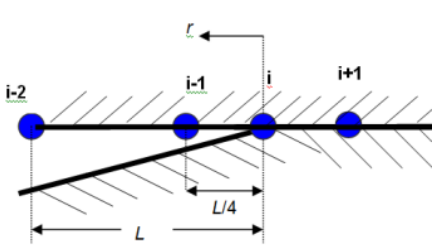

(b)

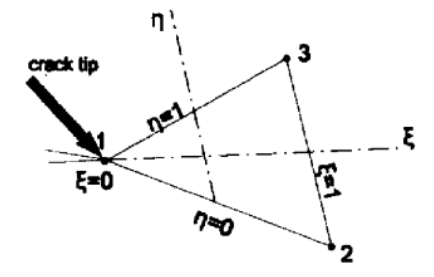

(c)

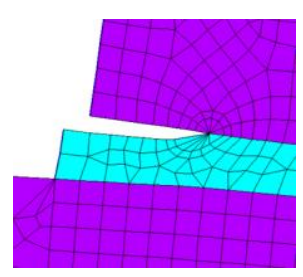

(d)

Figure 7. Fracture mechanics analysis: (a) FE mesh at a crack tip, (b) Quarter point, (c) General power singularity element and (d) Deformation near a crack tip.

\section{FATIGUE ANALYSIS}

Fatigue analysis combines stress analysis with either continuum damage mechanics for fatigue crack initiation analysis or fracture mechanics for fatigue crack propagation analysis. In continuum damage mechanics, the fatigue damage accumulation is represented by a damage variable $D$, which is equal to zero for a virgin material and 1 for a fully damaged material. The damage variable can be calculated from FE stress analysis results, providing that some damage material parameters are given. For low cycle fatigue, the damage variable $(D)$ is expressed as [17]:

$$
D=1-\left[1-A(\beta+m+1)\left(\Delta \sigma_{e q}\right)^{\beta+m} R_{V}^{\beta / 2} N\right] \frac{1}{\beta+m+1}
$$


Where $N$ is the number of cycles, $\Delta \sigma_{e q}$ is the range of von-Mises stress, $R_{V}$ is the triaxiality function, $m$ is the power constant in Ramberg-Osgood equation, and $A$ and $\beta$ are damage parameters, which can be determined experimentally. For given $N, m, A$ and $\beta$, the range of von-Mises stress $\Delta \sigma_{e q}$ and triaxiality function $R_{V}$ can be determined from stress analysis results, and therefore $D$ can be calculated using Equation (15). An example of the evolution of $D$ in an adhesive layer with fillet used for a scarf joint [18] is shown in Figure 8.
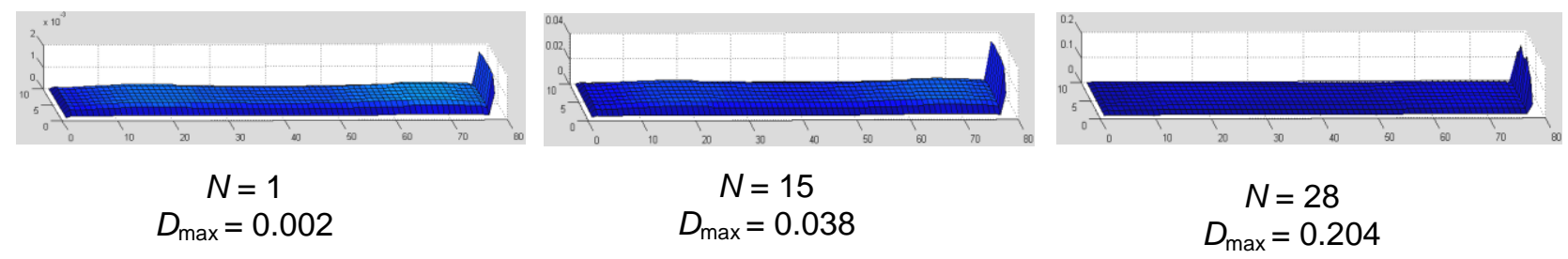

Figure 8. Fatigue damage evolution in adhesive layer

In fatigue crack propagation analysis, a crack growth equation (e.g. Paris law) is numerically integrated within a FE stress analysis. A modified Paris law that includes the threshold and accelerating crack growth regions is given by [19]:

$$
\frac{d a}{d N}=D G_{\max }^{n}\left[\frac{1-\left(\frac{G_{t h}}{G_{\max }}\right)^{n_{1}}}{1-\left(\frac{G_{\max }}{G_{c}}\right)^{n_{2}}}\right]
$$

Where $\mathrm{da} / \mathrm{d} N$ is the crack growth rate, $G_{\max }$ is the maximum strain energy release rate at a specific stress ratio, $G_{\mathrm{th}}$ is the fatigue threshold, $G_{\mathrm{c}}$ is the fracture toughness, and $n, n_{1}$ and $n_{2}$ are constants. A procedure that is used to numerically integrate the crack growth law in FE analysis is shown in Figure 9. This procedure has been implemented in the FE package ANSYS. The application of the crack propagation procedure to a single lap joint is shown in Figure 10 [19]. Only half of the joint was modelled with rotational symmetric boundary conditions in the mid-plane. The number of cycles to failure were calculated twice for each load value; a) using the total strain energy release rate $\left(G_{\max }\right.$ or $\left.G_{T}\right)$ and b) using the mode I strain energy release rate $\left(G_{1}\right)$.

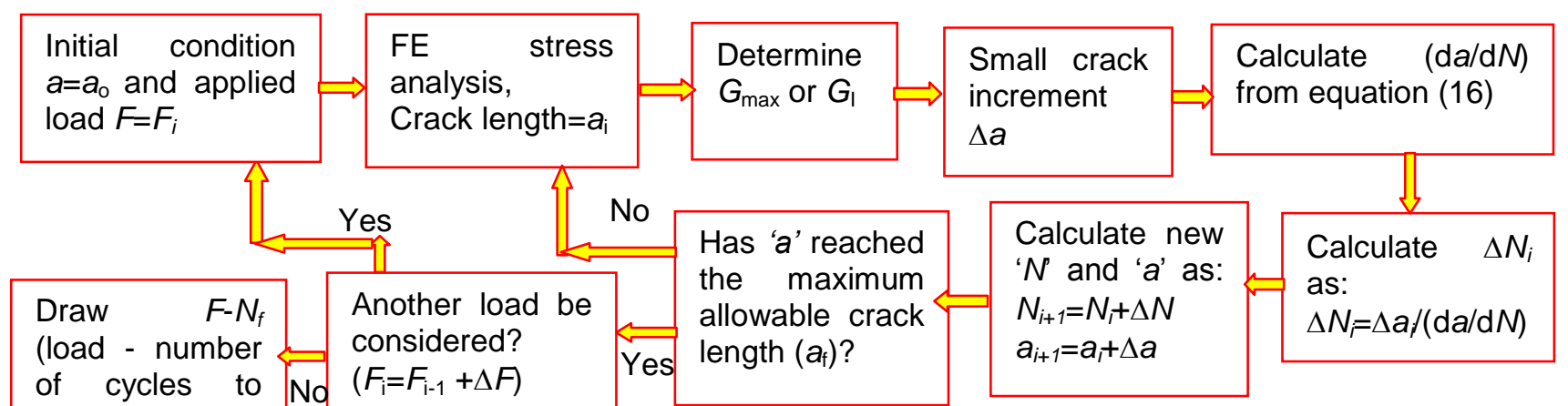

Figure 9. Fatigue crack propagation procedure
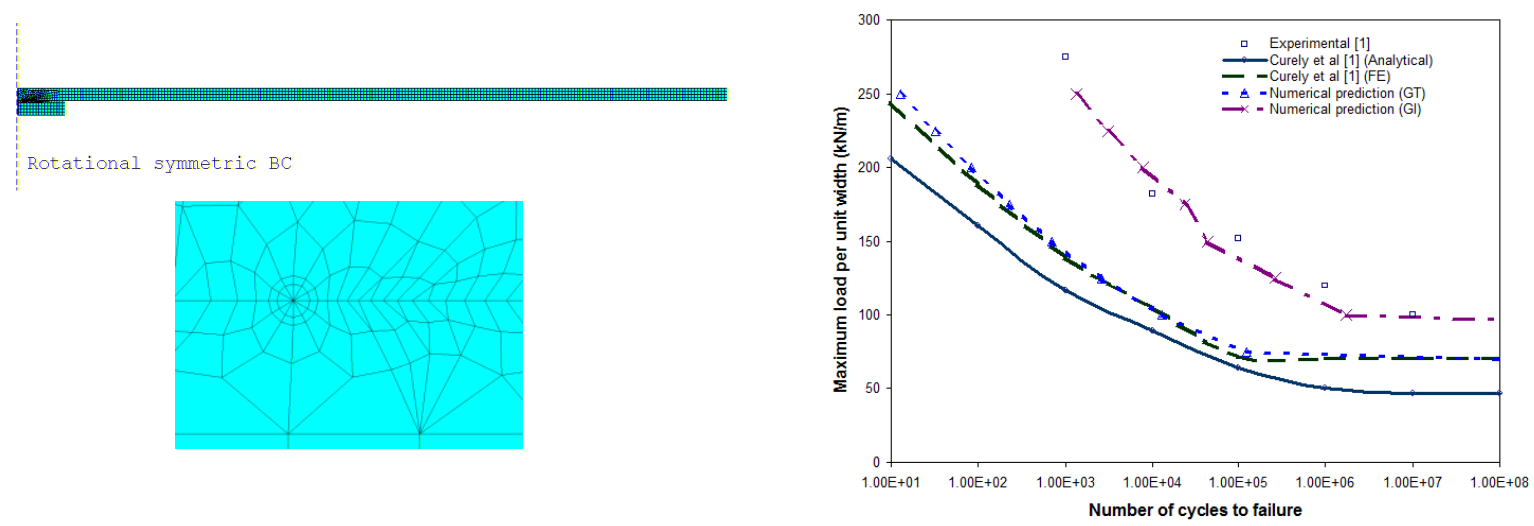

Figure 10. Fatigue crack propagation in a single lap joint 


\section{MODAL ANALYSIS}

FE Modal analysis is performed to determine the natural frequencies and the mode shapes of a structure in free vibration. The FE equation that should be solved in modal analysis is derived from the generalised equation of motion, which is given by:

$$
[M][\ddot{U}]+[C][\dot{U}]+[K \rrbracket[U]=[F]
$$

Where $[K]$ is the stiffness matrix, $[U]$ is the displacement vector, $[C]$ is the damping matrix, $[\dot{U}]$ is the first derivative of the displacement vector with respect to time (velocity vector), $[M]$ is the mass matrix, $[\ddot{U}]$ is the second derivative of the displacement vector with respect to time (acceleration vector) and $[F]$ is the force vector. For un-damped free vibration, both damping matrix and force vector are equal to zero and Equation (17) becomes:

$$
[M][\ddot{U}]+[K][U]=0
$$

The displacement time response solution of this differential Equation is $[U]=\left[U_{m}\right] \sin \left(\omega_{n} t+\psi\right)$, where the vector $\left[U_{m}\right]$ contains the maximum amplitude for each degree of freedom, $\omega_{n}$ is the angular frequency and $\psi$ is the phase angle. Differentiating the displacement twice with respect to time and substituting in Equation (18), yields:

$$
\left([K]-\omega_{n}^{2}[M]\right)\left[U_{m}\right]=0
$$

Equation (19) is an eigenvalue problem, which has ' $n$ ' number of eigenvalues (angular frequencies) and eigenvectors (mode shapes). The eigenvalue problem is solved using iterative numerical solution such as inverse iteration method, and tridiagonalisation and QR algorithm. An example of FE modal analysis is the free vibration of a pre-stressed concrete bridge, B14 [20]. The B14 bridge, built in 1971, is located between the two villages Peutie and Melsbroek and crosses the highway E19 between Brussels and Antwerp in Belgium. It has an overall length of $89 \mathrm{~m}$, a width of $13 \mathrm{~m}$ and two traffic lanes. The bridge has three spans and is supported by two piers and two abutments. A 3-D finite element model was constructed using solid elements and modal analysis was performed. Due to symmetry, only one-quarter of the bridge was modeled with appropriate symmetric or anti-symmetric boundary conditions in order to determine all symmetric and anti-symmetric modes of vibration. The FE mesh consists of 3321 brick elements and 4938 nodes. Figure 11 shows the first three mode shapes of the bridges B14.

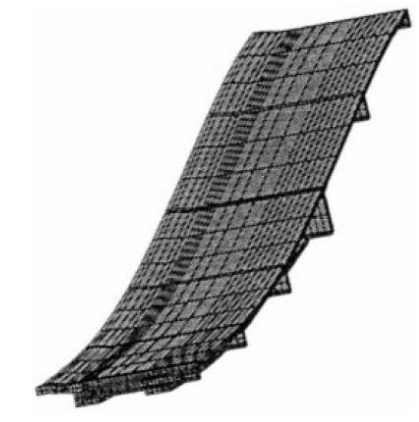

Mode $1-2.35 \mathrm{~Hz}$

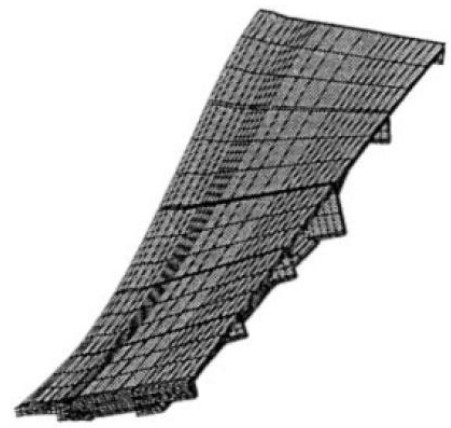

Mode $2-3.28 \mathrm{~Hz}$

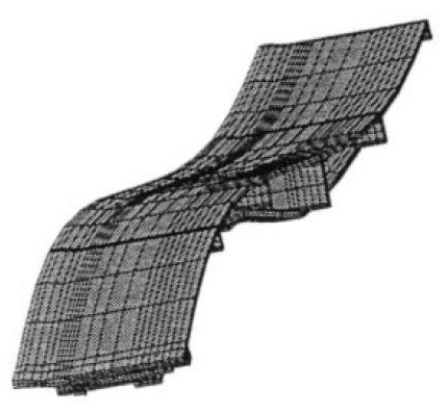

Mode $3-4.40 \mathrm{~Hz}$

Figurer 11. FE Modal analysis of bridge B14

\section{TRANSIENT DYNAMICS ANALYSIS}

Transient dynamics analysis, also known as time-history analysis, is concerned with the determination of the time response of a structure, i.e. displacements, strains, stresses as functions of time under the action of time dependent loads. The FE equation that should be solved in transient dynamics analysis is Equation (17), the generalised equation of motion. Because of the time dependent, Equation (17) is solved in time steps using numerical integration such as Euler integration scheme. In the explicit direct numerical integration scheme, the velocity and acceleration vectors at time step $t$ are approximated as:

$$
\begin{gathered}
{[\dot{U}(t)]=\frac{1}{2 \Delta t}[U(t+\Delta t)-U(t-\Delta t)]} \\
{[\ddot{U}(t)]=\frac{1}{\Delta t^{2}}[U(t+\Delta t)-2 U(t)+U(t-\Delta t)]}
\end{gathered}
$$


With appropriate initial conditions at $t=0$, solution of $[U]$ at different time steps can be found, using Equations (17), (20) and (21). As the time step becomes smaller, the numerical solution converges to the exact solution. An example of a FE transient dynamics analysis is shown in Figure 12, where a footbridge, Wilcott bridge, is excited using a walking pedestrian [21]. The Wilcott footbridge is a newly constructed FRP composite footbridge crossing the new A5 Nesscliffe Bypass near Shrewsbury, UK. Wilcott footbridge is a suspension bridge, has a single span of $50.24 \mathrm{~m}$ and provides a footway of $2.3 \mathrm{~m}$ wide. The finite element package ANSYS was used to simulate the transient dynamics response of the footbridge. 3-D beam elements (Figure 12(a)) were used to model all the structural members including; cross beams, deck, posts, cables and hangers. Mass elements were used to model handrails, ballast in the cells, and deck finishing. A time history analysis is performed to calculate the dynamic response of the footbridge under the action of a walking pedestrian at a frequency close to the second vertical natural frequency of the bridge $(1.6 \mathrm{~Hz})$. Humans walking pacing rate normally lies in the range $1.6-2.4 \mathrm{~Hz}$. The vertical dynamic load induced on the footbridge by a pedestrian taken from BS5400 is a pulsating moving load of: $F(t)=180 \sin (\omega . t) N$. The displacement time response in the mid-span of the bridge is shown in Figure 12(b).
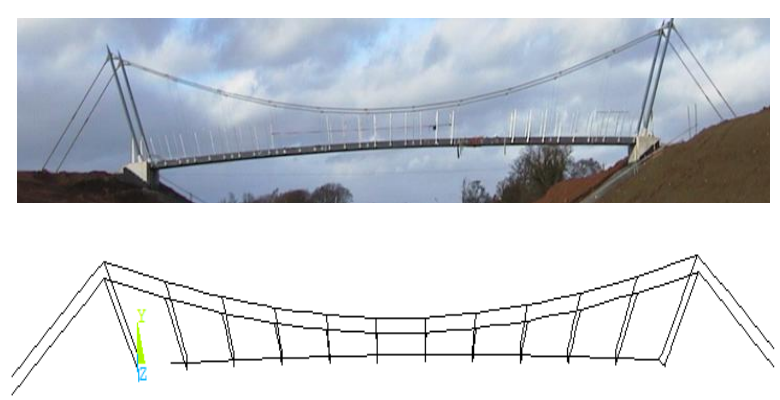

(a)

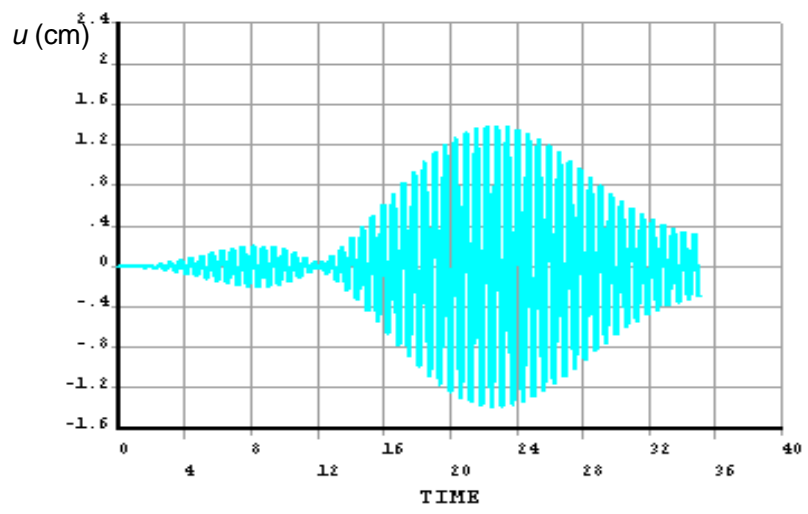

(b)

Figurer 12. Wilcott bridge: (a) FE model and (b) Mid-span response due to a walking pedestrian

\section{TRAFFIC FLOW ANALYSIS}

In traffic flow analysis, the degree of freedom is the traffic density. The governing partial differential equation of traffic flow is known by LWR (Lighthill, Witham and Richards) model. For one dimensional constant speed traffic flow, LWR equation is given by [22]:

$$
\frac{\partial k}{\partial t}+u_{o} \frac{\partial k}{\partial x}=0
$$

Where $k$ is the traffic density (vehicle/m), which is a function of time and space, and $u_{o}$ is the traffic speed $(\mathrm{m} / \mathrm{s})$. Applying variational formulation or Galerkin method to Equation (22), the FE equation in matrix form is obtained as:

$$
[A]\left[\frac{\partial k}{\partial t}\right]+[B][k]=0
$$

Again, the solution of Equation (23) is obtained in different time steps using numerical integration. An example of traffic flow analysis is a simulation of a $5 \mathrm{~km}$ road [22], where the boundary conditions at the beginning of the road $(x=0)$ are as shown in Figure 13(a). The convergence of traffic flow density at a distance of $2 \mathrm{~km}$ is plotted in Figure 13(b) by considering different element sizes $(\Delta x)$.

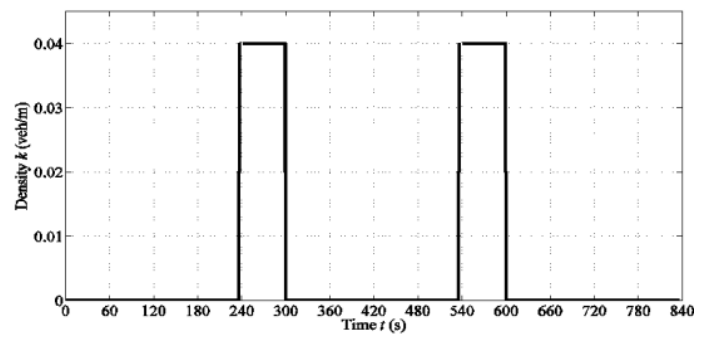

(a)

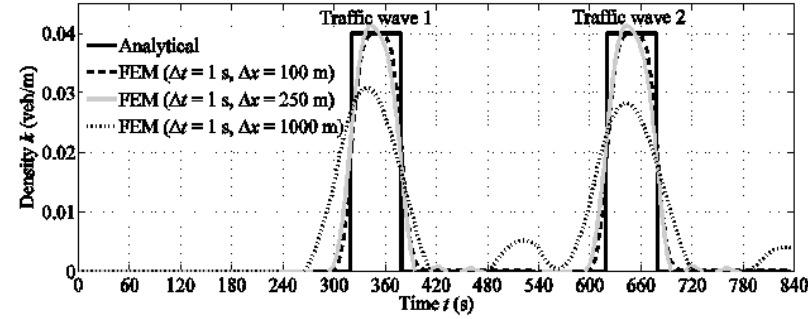

(b)

Figurer 13. FE traffic flow analysis: (a) Boundary conditions at the beginning of the road $x=0$ and (b) Convergence of density at $x=2 \mathrm{~km}$ as function of $\Delta x$ 


\section{CONCLUSIONS}

The Finite Element Method is a generic technique that can be used in several disciplines and can be applied to many physical engineering problems. Although many disciplines and applications have been covered in this paper, there are still other disciplines, which have not been considered, such as electromagnetic, acoustics and fluid mechanics, where FEM can provide very useful numerical solutions. Nowadays, FEA is well established numerical technique and many commercial software's are available for educational purposes and industrial uses. However, research and development into FEM is still going on in order to improve accuracy, facilitate the user interaction with the software and further implementation of specific applications.

\section{REFERENCES}

[1] R.D. Cook, D.S. Malkus and M.E. Plesha, Concept and applications of finite element analysis, John Wiley \& Sons, USA, Third edition, 1989.

[2] T.R. Chandrupatla and A.D. Belegundu, Introduction to finite elements in engineering, Pearson Education, USA, Third edition, 2002.

[3] S. Moaveni, Finite element analysis: theory and application with ANSYS, Pearson Education, USA, Second edition, 2003.

[4] M. M. Abdel Wahab, Stress analysis of a Manifold for Heypac pumps, Heypac Ltd, Internal Report, University of Surrey, December, 2000.

[5] M.M. Abdel Wahab, G.A.Parker and C.Wang, Modelling Rotary Sweeping Brushes and Analyzing Brush Characteristic using Finite Element Method, Finite Element in Analysis and Design, 43, 521-532, 2007.

[6] M. M. Abdel Wahab, S. A. Kandil, M. S. Abdel-kader and M. Moustafa, Stress intensity factor calculation for autofrettaged tube test-specimens using finite element method, $9^{\text {th }}$ International Conference on Aerospace Sciences \& Aviation Technology, ASAT- 9,Cairo, Egypt, May 8-10, 2001.

[7] A. W. E. Henham and M. M. Abdel Wahab, Railko Marine Integrated Bearings, Railko Ltd, Internal Report, University of Surrey, UK, June, 2001.

[8] M. M. Abdel Wahab, I. A. Ashcroft, A. D. Crocombe and S. J. Shaw, Diffusion of moisture in adhesively bonded joints, Journal of Adhesion, 77, 43-80, 2001.

[9] I. A. Ashcroft, M.M. Abdel Wahab and A.D. Crocombe, Predicting degradation in bonded composite joints using a semi-coupled FEA finite element method, Mechanics of Advanced Materials and Structures, 10, 227-248, 2003.

[10] R.S. Barsoum, On the use of isoparametric finite elements in linear elastic fracture mechanics, Inter. J. Numer. Meth. Engng, 10, 25-37, 1976.

[11] W. Ramberg and W.R. Osgood, Description of stress-strain curves by three parameters, Technical Note No. 902, National Advisory Committee For Aeronautics, Washington DC, 1943.

[12] M. M. Abdel Wahab and G. De Roeck, $A$ 3-D six-noded finite element containing a $\lambda$ singularity, International Journal of Fracture, 70, 347-356, 1995.

[13] M. M. Abdel Wahab and G. De Roeck, A 2-D five noded finite element to model power singularity, International Journal of Fracture, 74, 89-97, 1995.

[14] J. Martinez and J. Dominguez, Short Communication on the Use of Quarter-Point Boundary Elements for Stress Intensity Factor Computations, Int. J. Num. Meth. Engn., 20, 1941-1950, 1984.

[15] M. M. Abdel Wahab, On the use of fracture mechanics in designing a single lap adhesive joint, Journal of Adhesion Science and Technology (ISSN 0169-4243), Vol. 14, No. 6, pp. 851-866, 2000.

[16] M. M. Abdel Wahab, I. A. Ashcroft, A. D. Crocombe, D. J. Hughes and S. J. Shaw, The effect of environment on the fatigue of composite joints: Part 2 fatigue threshold prediction, Composites part A, 32(1), 59-69, 2001.

[17] M. M. Abdel Wahab, I. A. Ashcroft, A. D. Crocombe and S. J. Shaw, Prediction of fatigue threshold in adhesively bonded joints using damage mechanics and fracture mechanics, Journal of Adhesion Science and Technology, 15(7), 763-782, 2001.

[18] M. M. Abdel Wahab, I. Hilmy, I.A. Ashcroft and A.D. Crocombe, Damage parameters of adhesive joints with general triaxiality: Part 2 scarf joint analysis, J. of Adhesion Science and Technology, to appear, 2010.

[19] M.M. Abdel Wahab, I.A. Ashcroft, A.D. Crocombe and P.A. Smith, Numerical prediction of fatigue crack propagation lifetime in adhesively bonded structures, International Journal of Fatigue, 24(6), 705-709, 2002. [20] M. M. Abdel Wahab and G. De Roeck, Dynamic testing of prestressed concrete bridges and numerical verification, American Society of Civil Engineers, Journal of Bridge Engineering, 3(4), 159-169, 1998.

[21] R.A. Votsis, M. M. Abdel Wahab and M.K. Chryssanthopoulos, Simulation of damage scenarios in an FRP composite suspension footbridge, Key Engineering Materials, 293-294, 599-606, 2005.

[22] W. Ceulemans, M. M. Abdel Wahab, K. De Proft and G. Wets, Modelling traffic flow with constant speed using the Galerkin finite element method, World Congress on Engineering, The Proceedings of The International Conference of Applied and Engineering Mathematics, 993-999, London, 1-3 July, 2009. 